\title{
The role of syncytins in human reproduction and reproductive organ cancers
}

\author{
Bikem Soygur and Leyla Sati \\ Department of Histology and Embryology, Akdeniz University School of Medicine, Antalya, Turkey \\ Correspondence should be addressed to L Sati; Email: leylasati@yahoo.com
}

\begin{abstract}
Human life begins with sperm and oocyte fusion. After fertilization, various fusion events occur during human embryogenesis and morphogenesis. For example, the fusion of trophoblastic cells constitutes a key process for normal placental development. Fusion in the placenta is facilitated by syncytin 1 and syncytin 2 . These syncytins arose from retroviral sequences that entered the primate genome 25 million and more than 40 million years ago respectively. About $8 \%$ of the human genome consists of similar human endogenous retroviral (HERVs) sequences. Many are inactive because of mutations or deletions. However, the role of the few that remain transcriptionally active has not been fully elucidated. Syncytin proteins maintain cell-cell fusogenic activity based on env gene-mediated viral cell entry. In this review, we summarize how syncytins and their receptors are involved in fusion events during human reproduction. The significance of syncytins in tumorigenesis is also discussed.
\end{abstract}

Reproduction (2016) 152 R167-R178

\section{Introduction}

Cell fusion is an essential event during mammalian development for fertilization, placentation, formation of an immune defense system, development of skeletal muscle, and differentiation of macrophages into boneresorbing osteoclasts (Larsson et al. 2008). It is also important for tissue repair and cancer development and progression (Vassilopoulos et al. 2003, Larsson et al. 2007a). Cell fusion follows cell adhesion by receptor-ligand interactions, signaling molecules, and alpha helical bundles formed by fusogenic proteins. Among the many proteins involved in fusion events, syncytin proteins form similar alpha helical bundles that bring membranes close together and are encoded by endogenous retroviral genes in humans (Larsson et al. 2008, Evans 2012). Syncytin proteins, syncytin 1 and syncytin 2, belong to the human endogenous retrovirus (HERVs) family and were initially identified in human placenta due to their fusogenic activities. Syncytin $\mathrm{A}$ and $\mathrm{B}$, homologous to human syncytins, have also been identified in mice (Dupressoir et al. 2005) and are essential for normal murine placental development (Dupressoir et al. 2009, 2011).

Fertilization requires fusion of sperm and oocyte. Following implantation, the placenta forms and supports development of the embryo/fetus during intrauterine life. Fusion of mononuclear villous cytotrophoblast to form syncytiotrophoblast is essential for normal placental function (Esnault et al. 2008). We review, here, the role of the syncytins and their receptors in human reproduction and in reproductive organ tumors.

\section{Human endogenous retroviruses (HERVs)}

Infection of a host cell by an exogenous retrovirus causes the integration of retroviral DNA into the host cell's genome. In a case of germ cell infection, the inserted retroviral DNA can be subsequently inherited in a Mendelian fashion, and they are then termed 'endogenous retroviruses' (Prudhomme et al. 2005, Denner 2010, Stoye 2012, Mager \& Stoye 2015). Endogenous retroviral elements comprise approximately $8 \%$ of the human genome (Harris 1998, Griffiths 2001). Full-length HERVs are composed of $5^{\prime}$ and $3^{\prime}$ noncoding regions designated long-terminal repeats (LTRs), group-specific antigen (gag), polymerase ( $p o l)$ and envelope (env) genes (Fig. 1A). LTRs contain elements related to transcription initiation and termination such as enhancers, promoters and polyadenylation signals (Lower et al. 1996, Griffiths 2001, de Parseval \& Heidmann 2005, Prudhomme et al. 2005). Thus, the effect of HERVs can be associated with the influences on transcriptional activation or repression by LTR enhancers, alterations of tissue specificity, and increased expression of related genes (de Parseval \& Heidmann 2005). The gag gene encodes core structural proteins such as matrix, capsid and nucleocapsid that are participated in viral RNA encapsulation and particle formation. The pol gene encodes viral enzymes such as reverse transcriptase and integrase that are needed 


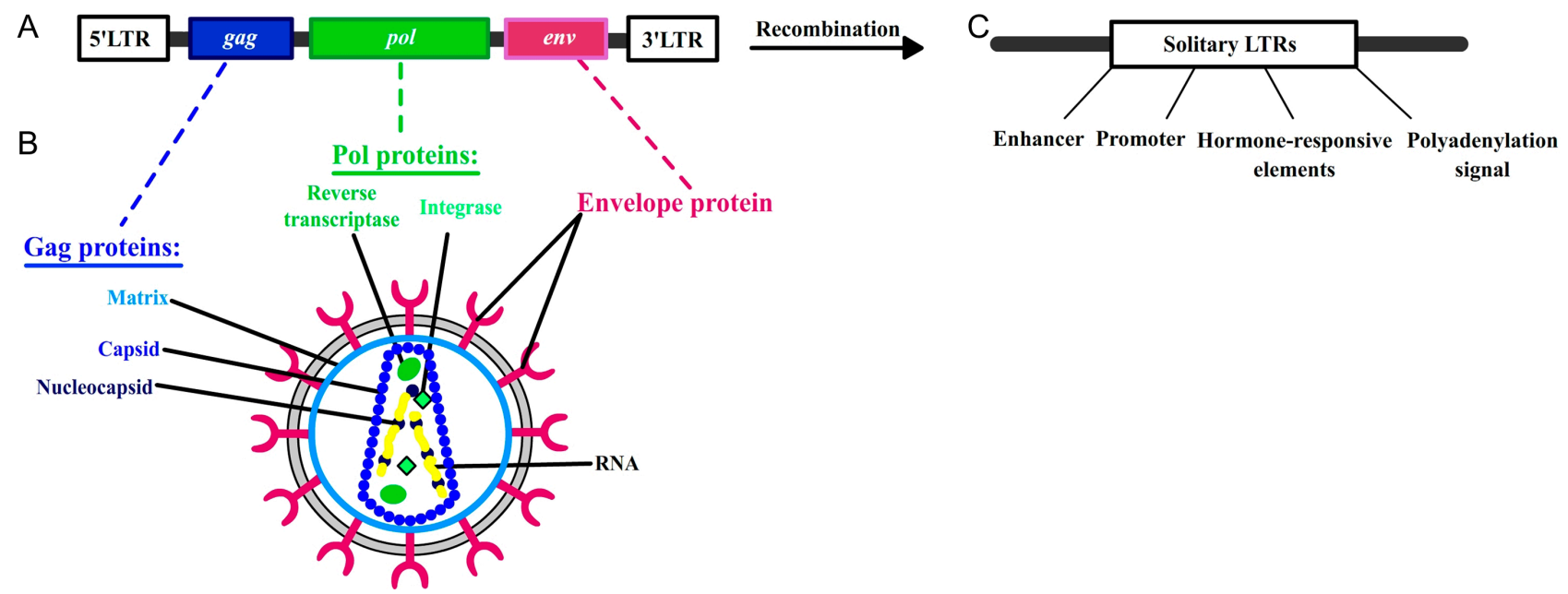

Figure 1 Generic structure of a full-length human endogenous retrovirus (A), its encoded proteins in general retrovirus structure (B), and solitary LTRs (C). 5' and 3' noncoding long-terminal repeats (LTRs), group-specific antigen gene (gag), polymerase (pol), and envelope gene (env).

for transcription of the viral RNA into double-stranded DNA and integration of the DNA produced by reverse transcriptase into the host's genome respectively. Finally, the env gene encodes viral envelope glycoprotein that is important for receptor recognition and membrane fusion (Lower et al. 1996, Prudhomme et al. 2005) (Fig. 1B).

env gene-mediated virus-host cell fusion is well studied. However, this fusion machinery can also lead to the fusion of neighboring cells in a receptor-dependent manner (Kjeldbjerg et al. 2010), similar to that of the viral entry to host cell (Izumida et al. 2015). Briefly, precursor ENV protein is processed by furin, or other proteases, into surface (SU) and transmembrane (TM) subunits. The SU subunit binds to its receptor in a neighboring cell, allowing the TM subunit to mediate membrane fusion between two cells (Kjeldbjerg et al. 2010).

In contrast to full-length ERVs, most ERV sequences lose the internal viral genes as a result of recombination between $5^{\prime}$ and $3^{\prime}$ LTRs and form 'solitary LTRs' (Griffiths 2001). Solitary LTRs are composed of enhancers, promoters, hormone-responsive elements and polyadenylation signals similar to all LTRs and can affect the expression patterns of neighboring genes (Vinogradova et al. 1997) (Fig. 1C). Most retroviral sequences contain in-frame stop codons or deletions that make them nonfunctional either at the transcriptional or post-transcriptional level. However, some retroviral elements still have large open reading frames (ORF) and retain their potential transcriptional capacity with important functions for the host's physiology (Rote et al. 2004, Denner 2010, Stoye 2012, Dewannieux \& Heidmann 2013).

\section{Syncytin proteins: two important endogenous retroviral gene products}

A systematic analysis of the human genome showed that 18 ENV genes encode a full-length ORF (de Parseval et al. 2003, Villesen et al. 2004). Among them, two retroviral gene products with crucial roles during mammalian development, syncytin 1 (HERV-W) and syncytin 2 (HERV-FRD), are encoded by ENV genes. These proteins were initially identified in human placenta (Mi et al. 2000, Blaise et al. 2003). Syncytin proteins are mainly expressed in the trophoblastic layer, which is an important contributor of normal placental architecture and trophoblast turnover (Mi et al. 2000, Malassine et al. 2007, Rawn \& Cross 2008). Syncytin 1 is a glycoprotein with cell fusogenic activity. It binds to its receptor, SLC1A5/ASCT2/RDR (a neutral amino acid transporter and type D mammalian retrovirus receptor), and promotes the fusion of cytotrophoblast cells to form the multinucleated syncytiotrophoblast layer (Blond et al. 2000, Malassine et al. 2005). Syncytin 2 entered the primate genome earlier than syncytin 1 (Voisset et al. 1999, Blaise et al. 2003, de Parseval et al. 2005). As this fusogenic retroviral gene was identified after syncytin 1, it was designated syncytin 2 (Blaise et al. 2003, de Parseval et al. 2005). Its receptor is a member of carbohydrate transporter superfamily MFSD2 (major facilitator superfamily domain containing 2) (Esnault et al. 2008). Syncytin 2 also plays roles in immunosuppression (Blaise et al. 2003, Mangeney et al. 2007, Rawn \& Cross 2008). Both syncytin proteins are less polymorphic when compared with other envelope proteins (de Parseval et al. 2005).

\section{The role of syncytin proteins in human reproduction}

Although many retroviral sequences are defective because of genetic modifications, syncytin sequences have been conserved, possibly due to beneficial reproductive functions (Bjerregaard et al. 2006). According to the 'Baton pass' hypothesis proposed by Imakawa et al. (2015), multiple successive endogenous retrovirus (ERV) variants incorporate into mammalian genomes in 
a locus-specific manner and take over the cell-fusion roles. Thus, some ERV insertions increased cell fusion in trophoblast resulting in enhanced reproductive success in placental mammals (Esnault et al. 2013, Lavialle et al. 2013, Imakawa et al. 2015). To date, many publications show that syncytins are involved in cell fusion (Mi et al. 2000, Frendo et al. 2003, Vargas et al. 2009, Liang et al. 2010), cell cycle (Huang et al. 2013), apoptosis (Knerr et al. 2007, Knerr et al. 2008, Huang et al. 2014b), and immunosuppression events (Mangeney et al. 2007) in human placenta. Also, altered expression of syncytin proteins have been reported in placental pathologies (Lee et al. 2001, Kudo et al. 2003, Chen et al. 2006, Ruebner et al. 2010, Vargas et al. 2011, Holder et al. 2012, Soygur et al. 2016) and different cancers (Larsson et al. 2007a, Strick et al. 2007, Maliniemi et al. 2013, Mo et al. 2013). As syncytins are initially defined in human placenta, we summarize their functions there, first.

\section{Syncytin 1 (HERV-W; ERVW-1) and human placentation}

The role of retroviral proteins, especially syncytins, in trophoblastic fusion process and placental morphogenesis was hypothesized about 15 years ago (Mi et al. 2000, Blaise et al. 2003). Mi et al. (2000) first identified syncytin 1 in the syncytiotrophoblast layer of human placental villi (Mi et al. 2000). They showed that when syncytin 1 is transfected into COS cells (CV-1 in origin and carrying the SV40 genetic material), syncytia formed consisting of many aggregated nuclei surrounded by an extended cytoplasm (Mi et al. 2000). When BeWo cells (trophoblast-derived choriocarcinoma cell line) are induced by forskolin to fuse and form syncytiotrophoblast-like cells, a five-fold increase in BeWo cell fusion is correlated with increased syncytin (ERVW-1) transcription (Mi et al. 2000). Thus, a role of syncytin 1 in placental cytotrophoblast fusion and its fusogenic properties in vitro is demonstrated (Mi et al. 2000). Following the discovery of syncytin 1, Blond et al. (2000) showed that transfection of different cell lines with syncytin 1 results in syncytia formation via the interaction of syncytin 1 and its receptor, SLC1A5 (Blond et al. 2000). SLC1A5 expression is reported in villous (Soygur et al. 2016) and extravillous trophoblast (Malassine et al. 2005).

After identification of the fundamental fusion role of syncytin 1 and upstream components in this signaling pathway, such as CD9 and cAMP/PKA (Muroi et al. 2009), many reports have shown the presence of syncytin 1 in the basal membrane of syncytiotrophoblast (Lee et al. 2001), cytotrophoblast (Blond et al. 2000, Smallwood et al. 2003, Muir et al. 2006, Soygur et al. 2016), and some stromal cells in the core of placental villi (Holder et al. 2012, Soygur et al. 2016). It is of interest to note that the presence of syncytin 1 in the stromal core of villi may further indicate some additional non-fusogenic functions of syncytin 1 . The presence of syncytin 1 in the apical microvillous membrane of villous trophoblast is also reported by our laboratory (Soygur et al. 2016). Malassine et al. (2005) showed syncytin 1 expression in all cell types of the extravillous phenotype lineage (Malassine et al. 2005). Cytotrophoblast in the tips of villi can differentiate into another type of trophoblast called the extravillous trophoblast. However, extravillous trophoblast cells are anchored and invade into the deeper layers of the decidua and maternal vascular bed (Cartwright et al. 2010). As cell-cell fusion of extravillous trophoblast does not occur at the maternalfetal interface, syncytin 1 expression in extravillous trophoblast arouses great interest. Glial cells missing 1 (GCM1) is an important placental transcription factor as chorionic trophoblast cells in Gcm 1-deficient placentas do not fuse to form syncytiotrophoblast (AnsonCartwright et al. 2000). Wang et al. (2012) identified the GCM1 target gene, HtrA4 (high-temperature requirement protein A4), and reported that HtrA4 protein mediates placental JAR (choriocarcinoma cell line) and BeWo cell invasion by cleaving the extracellular matrix (ECM) protein fibronectin. More importantly, their study also demonstrated that $\mathrm{HtrA} 4$ suppresses the cell-cell fusion mediated by syncytin 1 in transfected human embryonic kidney 293T cell line for the first time. Binding of HtrA4 PZD domain to the SU subunit of syncytin results in decreased syncytin 1 expression on the cell surface. While HtrA4 decreases syncytin 1-mediated cell fusion, it also supports the invasion of JAR and BeWo cells in vitro. Overall, the results indicated the importance of HtrA4 and syncytin 1 in extravillous trophoblast differentiation by preventing cell fusion and promoting invasion in extravillous trophoblast (Wang et al. 2012).

On the other hand, Huang et al. (2013) investigated the role of syncytin 1 in trophoblast proliferation (Huang et al. 2013). In this study, syncytin 1 knockdown by siRNA significantly inhibited BeWo cell growth and DNA synthesis in vitro. Analysis of G1/S cell cycle checkpoint regulators in syncytin 1 knockdown BeWo cells showed that there were decreased CDK4, E2F1, PCNA and c-Myc levels in contrast to increased p15 protein level after siRNA transfection. At 72-h posttransfection in syncytin 1 knockdown BeWo cells compared with control groups, there was an increased percentage of cells in G1 phase and a decreased percentage in $\mathrm{S}$ and $\mathrm{G} 2 / \mathrm{M}$ phases. These researchers therefore showed that syncytin 1 knockdown causes cell cycle arrest at the G1 phase (Huang et al. 2013). Because mononucleated cytotrophoblastic cells leave the cell cycle to differentiate into multinucleated syncytiotrophoblasts, they no longer have the ability to proliferate (Benirschke \& Kaufmann 2000). In case of insufficient syncytin 1 protein, cell cycle arrest may occur in cytotrophoblasts. The inadequate proliferation of cytotrophoblast and the absence of continuous fusion 
with syncytiotrophoblast may result in impairment of the syncytiotrophoblast layer. Therefore, one can speculate that syncytin 1 is possibly not only involved in the fusion of cytotrophoblast but also the proliferation of the cytotrophoblast via cell cycle. These independent properties of syncytin 1 (fusogenic and non-fusogenic) can maintain a balance between the 'cytotrophoblast

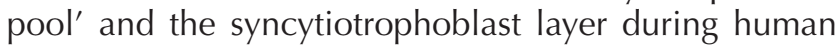
placental development.

Tolosa et al. (2012) showed a possible immune regulatory function of syncytin 1 in vitro (Tolosa et al. 2012). It is known that Th1 cytokines (e.g., TNF- $\alpha$, IFN- $-\gamma$ and IL-2) have harmful effects on the fetus and are downregulated during pregnancy (Raghupathy 1997). Tolosa et al. (2012) reported that lipopolysaccharide/ phytohemagglutinin (LPS/PHA)-stimulated Th1 cytokine responses (TNF- $\alpha$ and IFN- $\gamma$ ) and chemokine CXCL10 are inhibited by a syncytin 1 recombinant ectodomain in a human blood culture system. Moreover, $\mathrm{CRH}$ (corticotropin-releasing hormone) treatment of BeWo cells increases secreted exosomal syncytin 1 protein expression but not cellular syncytin 1 . These results suggest that the presence of syncytin 1 in placental exosomes might provide a mechanism for syncytin 1 to reach and interact with target cells of the maternal immune system during pregnancy (Tolosa et al. 2012).

Further studies are carried out to understand the potential roles of syncytin 1 in placental pathologies such as preeclampsia (PE) (Lee et al. 2001, Chen et al. 2006, Vargas et al. 2011, Holder et al. 2012), intrauterine growth restriction (IUGR), and gestational diabetes mellitus (GDM) (Soygur et al. 2016). PE is a pregnancyrelated disorder that affects approximately $2-7 \%$ of all pregnancies (Acien et al. 1990). In PE pregnancies, poor replacement of spiral artery wall by endovascular trophoblasts and insufficient placental circulation result in oxidative stress, hypoxia and endothelial dysfunction (Benirschke \& Kaufmann 2000). PE is diagnosed based on arterial hypertension and proteinuria in pregnancy (Wilson et al. 2003). Many reports have shown decreased expression and aberrant localization of syncytin 1 in PE placentas compared with healthy controls (Lee et al. 2001, Chen et al. 2006, Langbein et al. 2008, Vargas et al. 2014, Zhuang et al. 2014). Chiang et al. (2009) showed decreased levels of GCM1, syncytin 1 and placental growth factor, which are all crucial for syncytiotrophoblast formation and placental vasculogenesis in PE placentas. While hypoxia enables activation of glycogen synthase kinase 3 beta (GSK-3 $\beta$ ) in PE placenta, the PI3K-Akt pathway is inactivated under hypoxic condition in PE placental cells. Activated GSK$3 \beta$ phosphorylates GCM1, promotes its ubiquitination, and is then degraded by the $\mathrm{SCF}^{\mathrm{FBW} 2} \mathrm{E} 3$ ligase. As a result of disruption of the GCM1 transcription network, its target genes, syncytin 1 and placental growth factor, are decreased in a parallel manner (Chiang et al. 2009). Studies have also indicated a relationship between syncytin 1 and apoptosis in PE placentas (Ishihara et al. 2002, Huang et al. 2014b). Syncytin 1 knockdown in BeWo cells results in increased apoptosis in this carcinoma cell line of trophoblastic origin. Surprisingly, apoptosis in BeWo cells is mediated by apoptosisinducing factor (AIF), which is independent of caspase. Decreased syncytin 1, increased AIF and increased calpain1 protein levels in apoptotic cells of human PE placentas have also been shown (Huang et al. 2014b). Thus, changes in cell cycle progression and apoptosis caused by altered syncytin expression may cause abnormalities in PE placentas.

The role of syncytin 1 in intrauterine growth-restricted (IUGR) placentas has also been investigated. The chorionic villi surface areas are reduced compared with age-related controls, and a smaller interface between maternal and fetal tissues is observed in IUGR placentas (Biswas et al. 2008). Moreover, an abnormal cellular development of trophoblast and increased trophoblast apoptosis are also seen (Ishihara et al. 2002). Ruebner et al. (2010) showed decreased syncytin 1 levels in IUGR placentas, which may contribute to placental dysfunction in IUGR (Ruebner et al. 2010). Although deregulation of syncytin 1 in PE placental pathology has been comprehensively studied, the role of syncytin 1 in fetal growth retardation is less certain. Thus, further functional studies are needed to highlight the regulatory mechanisms of syncytin 1 in IUGR placentas.

A recent report has identified the first host cellencoded inhibitor protein, termed suppressyn, for mammalian cell fusion. Like syncytin, suppressyn is HERV-derived, placenta-specific and conserved during evolution. Suppressyn protein inhibits syncytin 1 -induced cell fusion by binding with the syncytin 1 receptor, SLC1A5, but does not affect syncytin 2-mediated syncytialization (Sugimoto et al. 2013). Unfortunately, the role and regulatory mechanisms of syncytin 1 in different placental pathologies are still not known clearly. Thus, identification and involvement of suppressyn in syncytin 1-mediated cell fusion during placentation might provide a useful approach to better understand the underlying molecular mechanisms in placental pathologies.

\section{Syncytin 2 (HERV-FRD; ERVFRD-1) and human placentation}

Syncytin 2 was initially characterized in human placenta by screening human sequence databases for endogenous envelope retroviral elements (Blaise et al. 2003). When 16 candidate $E N V$ retroviral genes were cloned in a eukaryotic expression vector and fusogenic activity was determined in transfected mammalian cells, syncytin 2 (ERVFRD-1) was discovered. Esnault et al. (2008) showed that syncytin 2 interacts with a different receptor (MFSD2) than syncytin 1 (Esnault et al. 2008). Further studies analyzed the amino acid sequence of syncytin 
2 and demonstrated an immunosuppressive domain (Mangeney et al. 2007). This domain may protect the fetus against the maternal immune system (Rawn \& Cross 2008, Lavialle et al. 2013). Data reported by Mangeney et al. (2007), using an in vivo tumor rejection assay, also supports the idea that syncytin 2 , but not syncytin 1 , has immunosuppressive activity. Tumorigenicity potential was assessed after syncytin 1- or syncytin 2-transduced MCA205 cells were engrafted to mice. Even though syncytin 2-transduced MCA205 cells formed large long-lasting tumors, syncytin 1-transduced MCA205 cells formed small tumors that were rapidly eliminated (Mangeney et al. 2007).

Many publications have tried to identify how syncytin 2 expression is regulated during healthy placental development. A recent study has demonstrated the regulation of syncytin 2 promoter activity via a CRE/AP-1 motif (Toufaily et al. 2015). bZIP (basic leucine zipper) transcription factors such as CREB2 (cAMP-response element binding protein 2) and JunD interact with the CRE/AP-1 motif and induce syncytin 2 expression in BeWo cells and primary villous cytotrophoblast isolated from term placentas (Toufaily et al. 2015). Malassine et al. (2007) and Esnault et al. (2008) showed that syncytin 2 expression is restricted to some cytotrophoblast cells in human first-trimester and term placenta respectively (Malassine et al. 2007, Esnault et al. 2008). In firsttrimester placenta, syncytin 2 protein expression is detected in cuboidal cytotrophoblast cells, whereas it is located in flat cytotrophoblast at term (Malassine et al. 2008). Moreover, it has also been shown that its transcript levels decrease in vitro when cytotrophoblast cells form syncytiotrophoblast. The presence of the MFSD2 transcripts in the syncytiotrophoblast layer is consistent with the 'in fusion' process of cytotrophoblasts into the syncytiotrophoblast (Esnault et al. 2008). We also showed the cellular localization of syncytin 2 and MFSD2 in syncytiotrophoblast, some of the stromal cells, and endothelium (Soygur et al. 2016). The different expression pattern from previous studies may suggest additional roles for syncytin 2 other than their fusogenic activity. Altered expression of both syncytin 1 and syncytin 2 envelope proteins are reported in PE (Vargas et al. 2011). The data indicated a correlation with disease severity in isolated primary trophoblast cells from control and PE placentas. A more dramatic decrease in syncytin 2 is seen compared with syncytin 1 (Vargas et al. 2011). Additionally, altered syncytin 2 localization in trisomy 21 -affected vs control placentas has also been reported (Malassine et al. 2008).

The presence of syncytin proteins at the surface of placental exosomes has been demonstrated (Tolosa et al. 2012). More recently, a possible relationship between placental exosome levels and PE pregnancies was also suggested (Vargas et al. 2014). Exosomes are small vesicles $(30-100 \mathrm{~nm})$ responsible for intercellular communications and several biological processes
(Valadi et al. 2007). Both syncytin 1 and syncytin 2 are detected at the surface of exosomes produced by placenta-derived villous trophoblasts and are taken up by other cell types (Tolosa et al. 2012, Vargas et al. 2014). Decreased syncytin 2 levels in serum-derived exosomes are found in PE versus normal pregnant women. As placental exosomes have been suggested to contribute to fetomaternal immunotolerance during pregnancy, the presence of syncytin 2 in placental exosomes might indicate its immunosuppressive role in exosomemediated immunotolerance in pregnant women (Vargas et al. 2014).

We studied the expression of syncytin proteins in placentas from women with gestational diabetes mellitus (GDM). GDM is characterized by abnormal glucose tolerance with onset, or first recognition, during pregnancy (O'Sullivan et al. 1985). GDM is associated with an increased rate of early pregnancy loss, morbidity, mortality, macrosomia and various metabolic abnormalities (Mondestin et al. 2002, Ruchat et al. 2013, West et al. 2013). Aside from its detrimental effects on mother and fetus, most placentas from GDM pregnancies show characteristic histological changes, such as villous immaturity and fibrinoid necrosis (Daskalakis et al. 2008). Our study showed reduced syncytin 2 and MFSD2 expressions in diabetic versus control human term placentas (Soygur et al. 2016). As previously indicated, the regulation of syncytin 1 in placental pathologies has been elucidated. However, the underlying molecular mechanisms for the deregulation of syncytin 2 in various placental pathologies are not yet clarified.

\section{The role of syncytin proteins in fertilization}

Fertilization is one of the most important cell fusion events in mammalian development. It involves multiple steps in which mature gametes meet and fuse at the correct time and place (Bjerregaard et al. 2014). Although human spermatozoa undergo many maturation processes during spermatogenesis, they leave the testis as immature cells functionally. Before fertilization, sperm pass through the epididymis where they gain forward motility and undergo further surface modifications, known as capacitation, in the female genital tract (Nixon et al. 2007).

Fertilization mainly consists of three steps: (1) acrosome reaction, (2) binding and penetration of zona pellucida (ZP), and finally (3) membrane fusion of sperm and oocyte (Kierszenbaum 2002). Fusogenic molecules play a role in sperm binding and penetration of the zona pellucida (Evans 2012). Although molecules that are involved in sperm:ZP binding are well characterized, the molecules for sperm and oocyte membrane fusion are still unknown. Many studies have tried to explain the role of ADAM proteins (a disintegrin and metalloproteinase), integrins, tetraspanins, and Izumo and Juno proteins in 
sperm and oocyte membrane fusion using knockout mice (Cho et al. 1998, Nishimura et al. 2001, Inoue et al. 2005, Nixon et al. 2007). As both mouse and human oocytes express ERV proteins on the oolemma and their expression decreases significantly after fertilization, it has been suggested that ERV genomes could play a role in sperm-egg binding and fusion (Nilsson et al. 1999).

\section{Syncytin 1 in fertilization}

Bjerregaard et al. (2014) first demonstrated the presence of syncytin 1 and its receptor, SLC1A5, in human gametes (Bjerregaard et al. 2014). They reported that syncyin 1 is expressed at both the mRNA and protein levels in human spermatozoa. It mainly localizes in the acrosomal region of the spermatozoa or at the equatorial segment. A slight staining of the midpiece and tail is also noted. Syncytin 1 receptor is observed in the acrosomal and tail regions. On the contrary, syncytin 1 expression is not detected in human oocytes. However, syncytin 1 receptor is present in oocytes and its mRNA expression increases proportionally with oocyte maturation (Bjerregaard et al. 2014). The presence of syncytin 1 and its receptor in human spermatozoa and the presence of the syncytin 1 receptor in human oocytes might reflect a potential fusogenic role in fertilization. A remarkable study conducted by Muroi et al. (2009) reinforced the possibility of syncytin 1 involvement in human fertilization. This study showed that the CD9 protein, a member of tetraspanin family, regulates GCM1 and syncytin 1 expressions via cAMP/PKA signaling in BeWo cells. CD9 is involved in membrane fusion of sperm and oocyte (Le Naour et al. 2000). Although the regulation of syncytin 1 expression by CD9 has not been proved in the membrane fusion of sperm and oocyte, it seems reasonable to investigate the potential role of syncytin 1 in fertilization.

To determine the role of syncytins in development, Dupressoir et al. (2009) knocked out the syncytin A gene (homologous to the human syncytin 1) in mice and showed that heterozygous syncytin $\mathrm{A}^{+/-}$mice are viable, fertile and without phenotypic defects. However, syncytin $\mathrm{A}^{-/-}$knockout mice die by E14.5 (Dupressoir et al. 2009). As it is not possible to produce syncytin 1-deficient human spermatozoa and systemic deletion of syncytin A in mice results in lethality, conditional deletion of the syncytin A gene in germ cells will need to be carried out to enlighten the roles of syncytins in fertilization.

\section{Syncytin 2 in fertilization}

There is no information regarding the presence of syncytin 2, or its receptor, in human gametes. As indicated previously, syncytin 2 possesses fusogenic activity and the immunosuppressive properties of syncytin 2 could potentially modulate immunological attacks on the oocyte membrane after sperm fusion. The immunosuppressive character of syncytin 2 may also have an effect on blocking further sperm-oocyte fusion (Prudhomme et al. 2005). However, further functional studies are needed to clarify the possible role of syncytin 2 , and its receptor, during sperm:oocyte membrane fusion.

\section{Syncytins in human reproductive organs and reproductive organ tumors}

Mi et al. (2000) examined 23 different human tissues for syncytin gene expression by using Northern blots and a weak expression pattern is reported in the testis besides a high expression in the placenta (Mi et al. 2000). Placenta- and testis-specific syncytin expression might be explained by DNA methylation. HERVs, as retrotransposons, are epigenetically regulated (Griffiths 2001) and DNA methylation generally suppresses their activity (Kudaka et al. 2008). As both human sperm and placenta show lower methylation levels than other tissues (Zhang et al. 1987, Nelissen et al. 2011), hypomethylation in placenta and testis might explain why these tissues are a rich source of actively transcribed HERVs. de Parseval et al. (2003) also analyzed the expression of 16 retroviral envelope genes, including syncytin 1 and syncytin 2, in 19 healthy tissues. Testis is found to be the only organ expressing all retroviral envelope genes at different mRNA levels (de Parseval et al. 2003). Additionally, Trejbalova et al. (2011) showed epigenetic deregulation of transcription and splicing of syncytins in testicular seminomas. Finally, Gimenez et al. (2010) analyzed the HERV transcriptome, including ERVW-1, in different normal and tumorigenic samples by using bisulfite sequencing and reported that six HERV-W loci are overexpressed in testicular cancer. Therefore, additional understanding of syncytins will give us more comprehensive information about their roles in male reproduction.

Studies have suggested that the human ovary exhibits absent/low expression of syncytin 1 (Menendez et al. 2004, Huang et al. 2014a). Menendez et al. (2004) reported increased syncytin 1 expression in malignant versus nonmalignant ovarian samples. This report also showed that syncytin 1 was hypomethylated in human ovarian cancers (Menendez et al. 2004). In line with the hypomethylated LTR region in the syncytin 1 promoter in endometriotic tissues, altered regulation of two DNA methyltransferase enzymes (DNMT3B and DNMT3B7) is also reported (Zhou et al. 2014). When considering that DNMT3B and DNMT3B7 are isoforms with and without methyltransferase activity, respectively, downregulation of DNMT3B and upregulation of DNMT3B7 could be responsible for epigenetic deregulation and syncytin 1 upregulation in endometriotic tissues (Zhou et al. 2014). Consequently, alterations in epigenetic regulation of syncytin 1 may 
Table $1 \mathrm{~A}$ brief summary of the literature with syncytins in the area of placental research.

\begin{tabular}{|c|c|c|}
\hline Reference & Syncytins & Outcome \\
\hline Mi et al. (2000) & Syncytin 1 & $\begin{array}{l}\text { First identification of the fusogenic role of syncytin } 1 . \\
\text { Cytoplasmic syncytin } 1 \text { expression in syncytiotrophoblast at mRNA level and its fusogenic activity } \\
\text { via cell culture experiments in vitro. }\end{array}$ \\
\hline Blond et al. (2000) & Syncytin 1 & $\begin{array}{l}\text { Syncytin } 1 \text { and type } \mathrm{D} \text { mammalian retrovirus receptor interaction during fusion process. } \\
\text { Localization of syncytin } 1 \text { mRNA in cytotrophoblast and syncytiotrophoblast in human placenta. }\end{array}$ \\
\hline Lee et al. (2001) & Syncytin 1 & $\begin{array}{l}\text { Decreased syncytin } 1 \text { mRNA in PE. } \\
\text { Determination of different localization patterns of syncytin } 1 \text { protein (apical syncytiotrophoblast } \\
\text { microvillous membrane) from normal placenta in PE. }\end{array}$ \\
\hline Knerr et al. (2002) & Syncytin 1 & Decreased syncytin 1 mRNA levels in PE and HELPP syndrome compared with normal placenta. \\
\hline Yu et al. (2002) & Syncytin 1 & $\begin{array}{l}\text { Syncytin } 1 \text { gene expression regulation by GCMa (placenta-specific transcription factor) in human } \\
\text { choriocarcinoma cell lines (BeWo and JEG3). }\end{array}$ \\
\hline Smallwood et al. (2003) & Syncytin 1 & $\begin{array}{l}\text { Decreased syncytin } 1 \text { protein expression at term compared with first-trimester human placenta. } \\
\text { Immunoreaction in extravillous trophoblasts, syncytiotrophoblast and cytotrophoblasts. }\end{array}$ \\
\hline Frendo et al. (2003) & Syncytin 1 & $\begin{array}{l}\text { Increased syncytin } 1 \text { mRNA and protein expression in primary cytotrophoblast differentiation into } \\
\text { syncytiotrophoblast in vitro. } \\
\text { Decreased trophoblast fusion and differentiation when syncytin } 1 \text { protein inhibition is enforced by } \\
\text { using specific antisense oligonucleotides. }\end{array}$ \\
\hline Kudo et al. (2003) & Syncytin 1 & Decreased syncytin 1 expression at low oxygen conditions and hypoxia. \\
\hline Blaise et al. (2003) & Syncytin 2 & First identification of syncytin 2. \\
\hline Malassine et al. (2005) & Syncytin 1 & $\begin{array}{l}\text { Presence of syncytin } 1 \text { protein in cytotrophoblastic cell columns, interstitial extravillous trophoblas- } \\
\text { tic cells, multinucleated giant cells and endovascular trophoblast in early pregnancy. } \\
\text { SLC1A5 expression in the extravillous phenotypes. }\end{array}$ \\
\hline Muir et al. (2006) & Syncytin 1 & $\begin{array}{l}\text { Syncytin } 1 \text { protein immunolocalization in syncytiotrophoblast, cytotrophoblast, invading interstitial } \\
\text { trophoblast cells, endovascular trophoblast, and placental bed giant cells of first- and second- } \\
\text { trimester placenta and choriocarcinoma cell lines. }\end{array}$ \\
\hline Chen et al. (2006) & Syncytin 1 & $\begin{array}{l}\text { Determination of syncytin } 1 \text { and its receptor mRNA levels in different gestational ages. } \\
\text { Reduced syncytin } 1 \text { mRNA in the cytotrophoblasts cultured under hypoxia and decreased protein } \\
\text { expression in PE compared with normal placenta. }\end{array}$ \\
\hline Malassine et al. (2007) & Syncytin 2 & $\begin{array}{l}\text { Syncytin } 2 \text { immunolocalization in some cytotrophoblast cells in first-trimester placenta. } \\
\text { Decreased syncytin } 2 \text { transcripts during in vitro differentiation of isolated villous trophoblastic cells. }\end{array}$ \\
\hline Mangeney et al. (2007) & Syncytin 2 & Demonstration of immunosuppressive activity of syncytin 2 . \\
\hline Knerr et al. $(2007,2008)$ & Syncytin 1 & Anti-apoptotic function of syncytin 1 by using $\mathrm{CHO}$ and HEK293 cells in vitro. \\
\hline Langbein et al. (2008) & Syncytin 1 & $\begin{array}{l}\text { Lower cell-cell fusion index, decreased syncytin } 1 \text { gene expression, and increased apoptosis in } \\
\text { cultured cytotrophoblasts and primary placental tissues from PE /HELLP-associated IUGR } \\
\text { placentas. }\end{array}$ \\
\hline Kudaka et al. (2008) & $\begin{array}{l}\text { Syncytin } 1 \text { and } \\
\text { syncytin } 2\end{array}$ & $\begin{array}{l}\text { Determination of lower syncytin } 1 \text { and syncytin } 2 \text { transcription levels in PIH than normotensive } \\
\text { pregnant women. } \\
\text { Detection of syncytin } 1 \text { transcripts in both cytotrophoblasts and syncytiotrophoblast. } \\
\text { Syncytin } 2 \text { transcripts in only cytotrophoblasts. }\end{array}$ \\
\hline Malassine et al. (2008) & Syncytin 2 & $\begin{array}{l}\text { Different syncytin } 2 \text { immunolocalization in trisomy-21-affected placentas compared with normal } \\
\text { placenta in second trimester of pregnancy. } \\
\text { Decreased syncytin } 2 \text { transcript levels during fusion of cytotrophoblasts into syncytiotrophoblast. }\end{array}$ \\
\hline Chen et al. (2008) & Syncytin 2 & $\begin{array}{l}\text { Determined increased syncytin } 2 \text { mRNA and protein levels as gestation progressed in normal } \\
\text { placenta. Decreased expression levels in PE compared with normal placentas. }\end{array}$ \\
\hline Esnault et al. (2008) & Sync & Discovery of MFSD2 as syncytin 2 receptor. \\
\hline Chiang et al. (2009) & Syncytin 1 & Disrupted GCM1 transcription network and reduced syncytin 1 levels in PE. \\
\hline Muroi et al. (2009) & Syncytin 1 & Syncytin 1 regulation by CD9 membrane protein in BeWo cells. \\
\hline Vargas et al. (2009) & $\begin{array}{l}\text { Syncytin } 1 \text { and } \\
\text { syncytin } 2\end{array}$ & $\begin{array}{l}\text { Comparison of the expression and functional implication of syncytin } 1 \text { and syncytin } 2 \text { in various } \\
\text { trophoblast and BeWo cells. }\end{array}$ \\
\hline Liang et al. (2010) & Syncytin 2 & $\begin{array}{l}\text { Identification of GCM1 as a critical factor for controlling cell fusion via transcriptional regulation of } \\
\text { syncytin } 2 \text { and MFSD2A gene expression in placenta. }\end{array}$ \\
\hline Ruebner et al. (2010) & $\begin{array}{l}\text { Syncytin } 1 \text { and } \\
\text { syncytin } 2\end{array}$ & $\begin{array}{l}\text { Decreased syncytin } 1 \text { and syncytin } 2 \text { levels in IUGR placenta compared with normal term placenta. } \\
\text { A similar decrease observed in cultured cytotrophoblasts from IUGR placenta compared with } \\
\text { normal term placenta. }\end{array}$ \\
\hline Vargas et al. (2011) & $\begin{array}{l}\text { Syncytin } 1 \text { and } \\
\text { syncytin } 2\end{array}$ & $\begin{array}{l}\text { Reduced syncytin } 1 \text { and syncytin } 2 \text { levels correlated with severity of PE. } \\
\text { A dramatic change in syncytin } 2 \text { expression. }\end{array}$ \\
\hline Holder et al. (2012) & Syncytin 1 & $\begin{array}{l}\text { Decreased syncytin } 1 \text { mRNA levels in first trimester compared with term placenta. } \\
\text { Altered syncytin } 1 \text { expression in PE, IUGR, and PE with IUGR. }\end{array}$ \\
\hline Wang et al. (2012) & Syncytin 1 & $\begin{array}{l}\text { Identification of the GCM1 target gene, HtrA4, and its interaction with syncytin } 1 \text { in suppression of } \\
\text { cell-cell fusion. }\end{array}$ \\
\hline Tolosa et al. (2012) & Syncytin 1 & The presence of syncytin 1 in human placental exosomes for the first time. \\
\hline l. (2013) & Syncytin 1 & $\begin{array}{l}\text { Identification of syncytin } 1 \text { role in cell cycle. } \\
\text { Syncytin } 1 \text { knockdown resulted in blocking the G1/S transition of cell cycle. }\end{array}$ \\
\hline Huang et al. (2014b) & Syncytin 1 & $\begin{array}{l}\text { Decreased syncytin } 1 \text { level and increased apoptosis by activation of AIF in BeWo cells suggesting its } \\
\text { role in PE placenta pathology. }\end{array}$ \\
\hline
\end{tabular}


Table 1 Continued.

\begin{tabular}{lll}
\hline Reference & Syncytins & Outcome \\
\hline Zhuang et al. (2014) & Syncytin 1 & $\begin{array}{l}\text { Hypermethylation of syncytin 1 promoter in PE compared with normal placentas. } \\
\text { Increased DNMT1 and DNMT3B3 mRNA and protein levels in PE placentas. }\end{array}$ \\
Vargas et al. (2014) & $\begin{array}{c}\text { Syncytin 1 and } \\
\text { syncytin 2 }\end{array}$ & $\begin{array}{c}\text { The presence of both syncytin proteins in placental exosomes and the altered syncytin 2 levels in } \\
\text { serum-derived exosomes in women with PE compared with normal pregnant women. }\end{array}$ \\
$\begin{array}{l}\text { Toufaily et al. (2015) } \\
\text { Soygur et al. (2016) }\end{array}$ & $\begin{array}{c}\text { Syncytin 2 } \\
\text { syncytin 2 }\end{array}$ & $\begin{array}{c}\text { The regulation of syncytin 2 promoter activity via a CRE/AP motif and transcription factors. } \\
\text { Reduced syncytin 2 and MFSD2 expression in gestational diabetic placenta compared with normal } \\
\text { placenta. }\end{array}$ \\
\hline
\end{tabular}

CHO, Chinese hamster ovary cell line; HEK 293, human embryonic kidney cells; HELLP, hemolysis, elevated liver enzymes, low platelets;

IUGR, intrauterine growth restriction; PE, preeclampsia; PIH, pregnancy-induced hypertension.

lead to ovarian pathology. In fact, the hypomethylation of CpG dinucleotides located within the promoter region of syncytin 1 might cause abnormal syncytin 1 expression in human ovary. Hypomethylation could result in increased fusogenic syncytin 1 protein expression, or other non-fusogenic consequences leading to ovarian pathology.

Strissel et al. (2012) revealed gene expression analysis of 21 envelope genes in human endometrium by qRT-PCR and immunohistochemistry. The data indicated that syncytin 1 immunolocalizes to the cytoplasm of glandular epithelial cells while syncytin 2 is detected in both glandular epithelial cells and ciliated surface tubal-type epithelial cells (Strissel et al. 2012). The expression of envelope genes in pathological conditions such as endometrial carcinoma (EnCa), hyperplasia and polyps is also investigated. Interestingly, syncytin 1 and syncytin 2 are found to be overexpressed at the pT2 tumor stage (tumor invasion into the uterine cervix, but no extension beyond the uterus) vs at the pT1b stage (tumor spreads to one-half or more of the myometrium) (Cancer 2010, Strissel et al. 2012). Moreover, the ERV-W 5' LTR promoter region, which regulates syncytin 1 expression, is found to be hypomethylated in ten patients diagnosed with EnCa. On the contrary, Strick et al. (2007) identified TGF- $\beta 1$ (Transforming growth factor beta 1) and TGF- $\beta 3$ (Transforming growth factor beta 3 ) as main regulative factors due to the data that steroid hormone-inducible TGF- $\beta 1$ and TGF- $\beta 3$ inhibit cell-cell fusion and reported that induced TGF- $\beta$ can override syncytin 1 -mediated cellcell fusions in EnCa (Strick et al. 2007). Thus, these results may suggest that some of the overexpressed envelope genes (including syncytin 1 and syncytin 2) can be used as markers for pathological conditions such as ovarian and EnCa in women.

Bjerregaard et al. (2006) showed the presence of syncytin 1 in breast cancer and breast cancer cell lines and also the syncytin 1 receptor in cancer cells and endothelial cells (Bjerregaard et al. 2006). Possibly, syncytin 1 and its receptor are involved in normal and cancer cell fusion. The fusion of normal host and cancer cells generates hybrids that contain a mixture of parental genomes (Mortensen et al. 2004). It is widely known that tumorigenicity of hybrids is generally suppressed due to activation of tumor suppressor genes transmitted from normal host cell (Harris et al. 1969, Wiener et al. 1974, Anderson \& Stanbridge 1993). However, tumorigenicity of hybrids may not be suppressed in all cases (Kohler \& Milstein 1975). A small fraction of hybrids possesses proliferation capacity, which is different from physiologically normal nonproliferating fused cells. It has been shown that proliferating hybrids (approximately $1 \%$ of cells) could be more drug resistant and metastatic than parental cancer cells (Duelli \& Lazebnik 2003). Thus, the physiopathology and unique features of hybrids may help us to understand tumorigenesis that result from impaired cell fusion. Syncytin 1 antisense treatment decreases syncytin

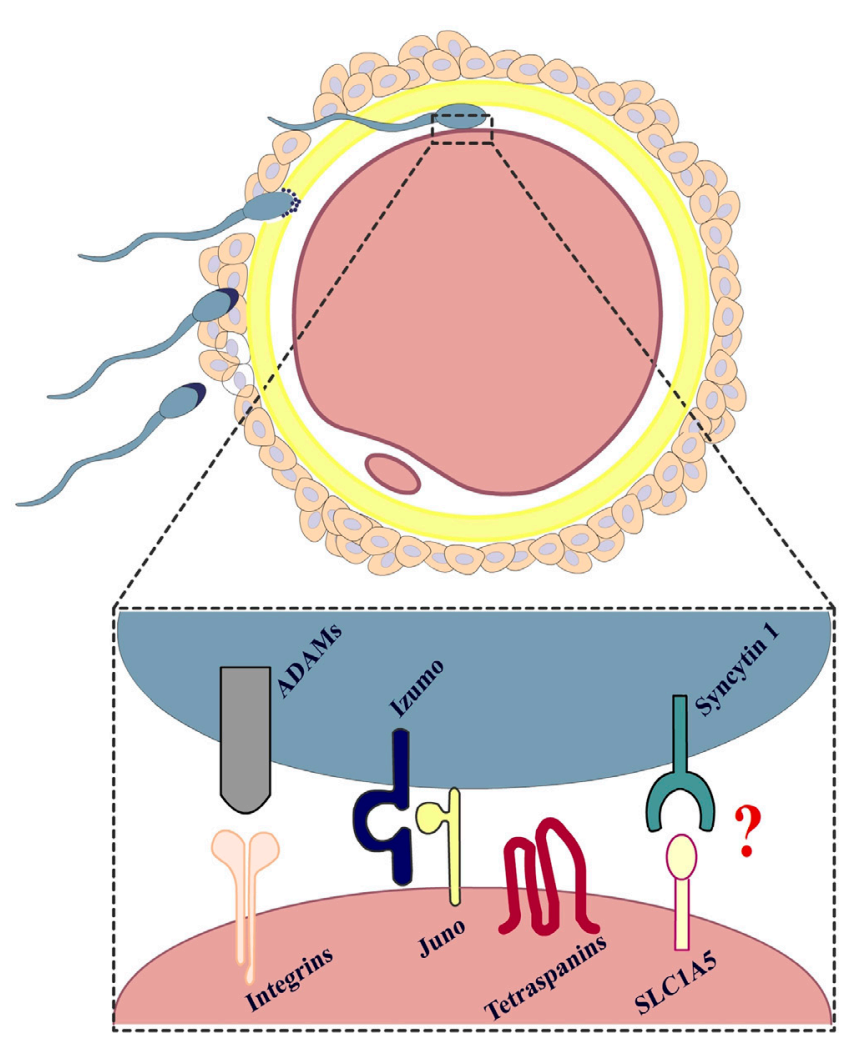

Figure 2 Schematic view of the molecules involving in sperm and oocyte membrane fusion during fertilization (Cho et al. 1998, Nishimura et al. 2001, Inoue et al. 2005, Nixon et al. 2007). Please note the presence of syncytin 1 on the sperm plasma membrane and its receptor SLC1A5 on the oolemma of oocyte. 
expression and inhibits fusions between MCF-7 (breast cancer cell line) and HUVEC cells (human umbilical vein endothelial cells). In addition, a syncytin 1 inhibitory peptide also inhibits fusions between cancer and endothelial cells in vitro. These results are first to show that syncytin is expressed in human cancer cells and are involved in cancer-endothelial cell fusions (Bjerregaard et al. 2006). Larsson et al. (2007b) determined whether syncytin 1 has a prognostic role in breast cancer in 165 premenopausal women with ductal cancers and 54 consecutively operated breast cancer patients (Larsson et al. 2007b). Syncytin 1 expression is confirmed in 38\% of the patients and its expression is demonstrated to be a positive prognostic factor in breast cancer patients (Larsson et al. 2007b).

\section{Conclusion}

In this review, we comprehensively analyzed the role of syncytin proteins in fertilization, placentation, and reproductive organ tumors, all of which are closely linked to human reproduction. Currently, syncytin proteins and their receptors have been studied extensively and found to be required in human placentation (Table 1). The occurrence of embryonic lethality in syncytin $\mathrm{A}^{-/-}$ knockout mice proves that syncytin genes are vital for early development. Although human and mouse development, and proteins involved in development may differ, functional experiments via syncytins knockout mouse mutants will definitively determine the function of syncytin genes in mammalian development and physiology (Dupressoir et al. 2009, 2011).

Even though the presence of endogenous retrovirus gene products such as ERV-3 (ERV3-1) and MuLV in human and mouse oocytes has been previously shown (Nilsson et al. 1999), ERV-3 is polymorphic in human population, thereby disfavoring a possible role during fertilization. However, determination of syncytin 1 in human sperm and its receptor in the human oocyte most likely suggests a role of syncytin 1 in sperm and oocyte fusion during fertilization (Bjerregaard et al. 2014). How gamete fusion is carried out by syncytins and their receptors is still unclear (Fig. 2). As syncytin $\mathrm{A}^{-/-}$mice show embryonic lethality, conditional experiments are needed to address this question. On the other hand, identification of possible roles of syncytins in reproductive organ tumors undoubtedly will help overcome the fertility problems related to these tumors.

In conclusion, it is still not known whether HERVs adapt to mammalian physiological needs or the viruses later gain important physiological functions. We believe that clarifying the roles of the fusogenic syncytin proteins in human development will help us to better understand their evolutionary significance and also their important roles in human reproduction and development.

\section{Declaration of interest}

The authors declare that there is no conflict of interest that could be perceived as prejudicing the impartiality of the research reported.

\section{Funding}

This research did not receive any specific grant from any funding agency in the public, commercial or not-for-profit sector.

\section{Acknowledgements}

The authors are grateful to James McGrath, MD, PhD, from Yale University School of Medicine for reviewing the manuscript.

\section{References}

Acien P, Lloret G \& Lloret M 1990 Perinatal morbidity and mortality in pregnancy hypertensive disorders: prognostic value of the clinical and laboratory findings. International Journal of Gynecology and Obstetrics 32 229-235. (doi:10.1016/0020-7292(90)90350-T)

American Joint Committee on Cancer 2010 AJCC Cancer Staging Manual. New York, NY, USA: Springer.

Anderson MJ \& Stanbridge EJ 1993 Tumor suppressor genes studied by cell hybridization and chromosome transfer. FASEB Journal 7 826-833.

Anson-Cartwright L, Dawson K, Holmyard D, Fisher SJ, Lazzarini RA \& Cross JC 2000 The glial cells missing-1 protein is essential for branching morphogenesis in the chorioallantoic placenta. Nature Genetics $\mathbf{2 5}$ 311-314. (doi:10.1038/77076)

Benirschke K \& Kaufmann P 2000 Pathology of the Human Placenta. New York, NY, USA: Springer.

Biswas S, Ghosh SK \& Chhabra S 2008 Surface area of chorionic villi of placentas: an index of intrauterine growth restriction of fetuses. Journal of Obstetrics and Gynaecology Research 34 487-493. (doi:10.1111/ j.1447-0756.2008.00719.x)

Bjerregaard B, Holck S, Christensen IJ \& Larsson LI 2006 Syncytin is involved in breast cancer-endothelial cell fusions. Cellular and Molecular Life Sciences 63 1906-1911. (doi:10.1007/s00018-006-6201-9)

Bjerregaard B, Lemmen JG, Petersen MR, Ostrup E, Iversen LH, Almstrup K, Larsson LI \& Ziebe S 2014 Syncytin-1 and its receptor is present in human gametes. Journal of Assisted Reproduction and Genetics 31 533-539. (doi:10.1007/s10815-014-0224-1)

Blaise S, de Parseval N, Benit L \& Heidmann T 2003 Genomewide screening for fusogenic human endogenous retrovirus envelopes identifies syncytin 2, a gene conserved on primate evolution. PNAS 100 13013-13018. (doi:10.1073/pnas.2132646100)

Blond JL, Lavillette D, Cheynet V, Bouton O, Oriol G, Chapel-Fernandes S, Mandrand B, Mallet F \& Cosset FL 2000 An envelope glycoprotein of the human endogenous retrovirus HERV-W is expressed in the human placenta and fuses cells expressing the type $\mathrm{D}$ mammalian retrovirus receptor. Journal of Virology 74 3321-3329. (doi:10.1128/JVI.74.7.33213329.2000)

Cartwright JE, Fraser R, Leslie K, Wallace AE \& James JL 2010 Remodelling at the maternal-fetal interface: relevance to human pregnancy disorders. Reproduction 140 803-813. (doi:10.1530/REP-10-0294)

Chen CP, Wang KG, Chen CY, Yu C, Chuang HC \& Chen H 2006 Altered placental syncytin and its receptor ASCT2 expression in placental development and pre-eclampsia. BJOG 113 152-158. (doi:10.1111/ j.1471-0528.2005.00843.x)

Chen CP, Chen LF, Yang SR, Chen CY, Ko CC, Chang GD \& Chen H 2008 Functional characterization of the human placental fusogenic membrane protein syncytin 2. Biology of Reproduction 79 815-823. (doi:10.1095/ biolreprod.108.069765)

Chiang MH, Liang FY, Chen CP, Chang CW, Cheong ML, Wang LJ, Liang CY, Lin FY, Chou CC \& Chen H 2009 Mechanism of hypoxia-induced GCM1 degradation: implications for the pathogenesis of preeclampsia. 
Journal of Biological Chemistry 284 17411-17419. (doi:10.1074/jbc. M109.016170)

Cho C, Bunch DO, Faure JE, Goulding EH, Eddy EM, Primakoff P \& Myles DG 1998 Fertilization defects in sperm from mice lacking fertilin beta. Science 281 1857-1859. (doi:10.1126/science.281.5384.1857)

Daskalakis G, Marinopoulos S, Krielesi V, Papapanagiotou A, Papantoniou N, Mesogitis S \& Antsaklis A 2008 Placental pathology in women with gestational diabetes. Acta Obstetricia et Gynecologica Scandinavica 87 403-407. (doi:10.1080/00016340801908783)

de Parseval N \& Heidmann T 2005 Human endogenous retroviruses: from infectious elements to human genes. Cytogenetic and Genome Research 110 318-332. (doi:10.1159/000084964)

de Parseval N, Lazar V, Casella JF, Benit L \& Heidmann T 2003 Survey of human genes of retroviral origin: identification and transcriptome of the genes with coding capacity for complete envelope proteins. Journal of Virology 77 10414-10422. (doi:10.1128/JVI.77.19.1041410422.2003)

de Parseval N, Diop G, Blaise S, Helle F, Vasilescu A, Matsuda F \& Heidmann T 2005 Comprehensive search for intra- and inter-specific sequence polymorphisms among coding envelope genes of retroviral origin found in the human genome: genes and pseudogenes. BMC Genomics 6 117. (doi:10.1186/1471-2164-6-117)

Denner J 2010 Endogenous retroviruses. In Retroviruses Molecular Biology, Genomics and Pathogenesis. Norfolk, UK: Caister Academic Press.

Dewannieux M \& Heidmann T 2013 Endogenous retroviruses: acquisition, amplification and taming of genome invaders. Current Opinion in Virology 3 646-656. (doi:10.1016/j.coviro.2013.08.005)

Duelli D \& Lazebnik Y 2003 Cell fusion: a hidden enemy? Cancer Cell 3 445-448. (doi:10.1016/S1535-6108(03)00114-4)

Dupressoir A, Marceau G, Vernochet C, Benit L, Kanellopoulos C, Sapin V \& Heidmann T 2005 Syncytin-A and syncytin-B, two fusogenic placentaspecific murine envelope genes of retroviral origin conserved in Muridae. PNAS 102 725-730. (doi:10.1073/pnas.0406509102)

Dupressoir A, Vernochet C, Bawa O, Harper F, Pierron G, Opolon P \& Heidmann T 2009 Syncytin-A knockout mice demonstrate the critical role in placentation of a fusogenic, endogenous retrovirus-derived, envelope gene. PNAS 106 12127-12132. (doi:10.1073/pnas.0902925106)

Dupressoir A, Vernochet C, Harper F, Guegan J, Dessen P, Pierron G \& Heidmann T 2011 A pair of co-opted retroviral envelope syncytin genes is required for formation of the two-layered murine placental syncytiotrophoblast. PNAS $\mathbf{1 0 8}$ E1164-E1173. (doi:10.1073/pnas. 1112304108)

Esnault C, Priet S, Ribet D, Vernochet C, Bruls T, Lavialle C, Weissenbach J \& Heidmann T 2008 A placenta-specific receptor for the fusogenic, endogenous retrovirus-derived, human syncytin-2. PNAS 105 17532-17537. (doi:10.1073/pnas.0807413105)

Esnault C, Cornelis G, Heidmann O \& Heidmann T 2013 Differential evolutionary fate of an ancestral primate endogenous retrovirus envelope gene, the EnvV syncytin, captured for a function in placentation. PLOS Genetics 9 e1003400. (doi:10.1371/journal.pgen.1003400)

Evans JP 2012 Sperm-egg interaction. Annual Review of Physiology 74 477-502. (doi:10.1146/annurev-physiol-020911-153339)

Frendo JL, Olivier D, Cheynet V, Blond JL, Bouton O, Vidaud M, Rabreau M, Evain-Brion D \& Mallet F 2003 Direct involvement of HERV-W Env glycoprotein in human trophoblast cell fusion and differentiation. Molecular and Cellular Biology 23 3566-3574. (doi:10.1128/MCB.23.10.3566-3574.2003)

Gimenez J, Montgiraud C, Pichon JP, Bonnaud B, Arsac M, Ruel K, Bouton O \& Mallet F 2010 Custom human endogenous retroviruses dedicated microarray identifies self-induced HERV-W family elements reactivated in testicular cancer upon methylation control. Nucleic Acids Research 38 2229-2246. (doi:10.1093/nar/gkp1214)

Griffiths DJ 2001 Endogenous retroviruses in the human genome sequence. Genome Biology 2 REVIEWS1017. (doi:10.1186/gb-2001-26-reviews1017)

Harris JR 1998 Placental endogenous retrovirus (ERV): structural, functional, and evolutionary significance. BioEssays 20 307-316. (doi:10.1002/(SICI)1521-1878(199804)20:4<>1.0.CO;2-X)

Harris H, Miller OJ, Klein G, Worst P \& Tachibana T 1969 Suppression of malignancy by cell fusion. Nature 223 363-368. (doi:10.1038/223363a0)

Holder BS, Tower CL, Abrahams VM \& Aplin JD 2012 Syncytin 1 in the human placenta. Placenta 33 460-466. (doi:10.1016/j. placenta.2012.02.012)
Huang Q, Li J, Wang F, Oliver MT, Tipton T, Gao Y \& Jiang SW 2013 Syncytin-1 modulates placental trophoblast cell proliferation by promoting G1/S transition. Cellular Signalling 25 1027-1035. (doi:10.1016/j.cellsig.2013.01.008)

Huang Q, Chen H, Li J, Oliver M, Ma X, Byck D, Gao Y \& Jiang SW 2014a Epigenetic and non-epigenetic regulation of syncytin-1 expression in human placenta and cancer tissues. Cellular Signalling 26 648-656. (doi:10.1016/j.cellsig.2013.11.002)

Huang Q, Chen H, Wang F, Brost BC, Li J, Gao Y, Li Z \& Jiang SW $2014 b$ Reduced syncytin-1 expression in choriocarcinoma BeWo cells activates the calpain1-AIF-mediated apoptosis, implication for preeclampsia. Cellular and Molecular Life Sciences 71 3151-3164. (doi:10.1007/ s00018-013-1533-8)

Imakawa K, Nakagawa S \& Miyazawa T 2015 Baton pass hypothesis: successive incorporation of unconserved endogenous retroviral genes for placentation during mammalian evolution. Genes to Cells 20 771-788. (doi:10.1111/gtc.12278)

Inoue N, Ikawa M, Isotani A \& Okabe M 2005 The immunoglobulin superfamily protein Izumo is required for sperm to fuse with eggs. Nature 434 234-238. (doi:10.1038/nature03362)

Ishihara N, Matsuo H, Murakoshi H, Laoag-Fernandez JB, Samoto T \& Maruo T 2002 Increased apoptosis in the syncytiotrophoblast in human term placentas complicated by either preeclampsia or intrauterine growth retardation. American Journal of Obstetrics and Gynecology 186 158-166. (doi:10.1067/mob.2002.119176)

Izumida M, Kamiyama H, Suematsu T, Honda E, Koizumi Y, Yasui K, Hayashi H, Ariyoshi K \& Kubo Y 2015 Fragments of target cells are internalized into retroviral envelope protein-expressing cells during cell-cell fusion by endocytosis. Frontiers in Microbiology 61552. (doi:10.3389/fmicb.2015.01552)

Kierszenbaum AL 2002 Histology and Cell Biology: An Introduction to Pathology. Philadelphia, PA, USA: Elsevier - Health Sciences Division.

Kjeldbjerg AL, Bahrami S \& Pedersen FS 2010 Retroviruses and cell fusion: overview. In Cell Fusions Regulation and Control. New York, NY, USA: Springer.

Knerr I, Beinder E \& Rascher W 2002 Syncytin, a novel human endogenous retroviral gene in human placenta: evidence for its dysregulation in preeclampsia and HELLP syndrome. American Journal of Obstetrics and Gynecology 186 210-213. (doi:10.1067/mob.2002.119636)

Knerr I, Schnare M, Hermann K, Kausler S, Lehner M, Vogler T, Rascher W \& Meissner U 2007 Fusiogenic endogenous-retroviral syncytin-1 exerts anti-apoptotic functions in staurosporine-challenged $\mathrm{CHO}$ cells. Apoptosis 12 37-43. (doi:10.1007/s10495-006-0329-9)

Knerr I, Soder S, Licha E, Aigner T \& Rascher W 2008 Response of HEK293 and $\mathrm{CHO}$ cells overexpressing fusiogenic syncytin-1 to mitochondrionmediated apoptosis induced by antimycin A. Journal of Cellular Biochemistry 105 766-775. (doi:10.1002/jcb.v105:3)

Kohler G \& Milstein C 1975 Continuous cultures of fused cells secreting antibody of predefined specificity. Nature 256 495-497. (doi:10.1038/256495a0)

Kudaka W, Oda T, Jinno Y, Yoshimi N \& Aoki Y 2008 Cellular localization of placenta-specific human endogenous retrovirus (HERV) transcripts and their possible implication in pregnancy-induced hypertension. Placenta 29 282-289. (doi:10.1016/j.placenta.2007.11.009)

Kudo Y, Boyd CA, Sargent IL \& Redman CW 2003 Hypoxia alters expression and function of syncytin and its receptor during trophoblast cell fusion of human placental BeWo cells: implications for impaired trophoblast syncytialisation in pre-eclampsia. Biochimica et Biophysica Acta 1638 63-71. (doi:10.1016/S0925-4439(03)00043-7)

Langbein M, Strick R, Strissel PL, Vogt N, Parsch H, Beckmann MW \& Schild RL 2008 Impaired cytotrophoblast cell-cell fusion is associated with reduced Syncytin and increased apoptosis in patients with placental dysfunction. Molecular Reproduction and Development 75 175-183. (doi:10.1002/(ISSN)1098-2795)

Larsson LI, Bjerregaard B, Wulf-Andersen L \& Talts JF 2007a Syncytin and cancer cell fusions. Scientific World Journal 7 1193-1197. (doi:10.1100/ tsw.2007.212)

Larsson LI, Holck S \& Christensen IJ 2007b Prognostic role of syncytin expression in breast cancer. Human Pathology 38 726-731. (doi:10.1016/j.humpath.2006.10.018)

Larsson LI, Bjerregaard B \& Talts JF 2008 Cell fusions in mammals. Histochemistry and Cell Biology 129 551-561. (doi:10.1007/s00418008-0411-1) 
Lavialle C, Cornelis G, Dupressoir A, Esnault C, Heidmann O, Vernochet C \& Heidmann T 2013 Paleovirology of 'syncytins', retroviral env genes exapted for a role in placentation. Philosophical Transactions of the Royal Society of London. Series B, Biological Sciences 368 20120507. (doi:10.1098/rstb.2012.0507)

Le Naour F, Rubinstein E, Jasmin C, Prenant M \& Boucheix C 2000 Severely reduced female fertility in CD9-deficient mice. Science $\mathbf{2 8 7}$ 319-321. (doi:10.1126/science.287.5451.319)

Lee X, Keith JC Jr, Stumm N, Moutsatsos I, McCoy JM, Crum CP, Genest D, Chin D, Ehrenfels C, Pijnenborg R et al. 2001 Downregulation of placental syncytin expression and abnormal protein localization in pre-eclampsia. Placenta 22 808-812. (doi:10.1053/ plac.2001.0722)

Liang CY, Wang LJ, Chen CP, Chen LF, Chen YH \& Chen H 2010 GCM1 regulation of the expression of syncytin 2 and its cognate receptor MFSD2A in human placenta. Biology of Reproduction 83 387-395. (doi:10.1095/biolreprod.110.083915)

Lower R, Lower J \& Kurth R 1996 The viruses in all of us: characteristics and biological significance of human endogenous retrovirus sequences. PNAS 93 5177-5184. (doi:10.1073/pnas.93.11.5177)

Mager DL \& Stoye JP 2015 Mammalian endogenous retroviruses. Microbiology Spectrum 3 MDNA3-0009-2014. (doi:10.1128/ microbiolspec.mdna3-0009-2014)

Malassine A, Handschuh K, Tsatsaris V, Gerbaud P, Cheynet V, Oriol G, Mallet F \& Evain-Brion D 2005 Expression of HERV-W Env glycoprotein (syncytin) in the extravillous trophoblast of first trimester human placenta. Placenta 26 556-562. (doi:10.1016/ j.placenta.2004.09.002)

Malassine A, Blaise S, Handschuh K, Lalucque H, Dupressoir A, Evain-Brion D \& Heidmann T 2007 Expression of the fusogenic HERV-FRD Env glycoprotein (syncytin 2) in human placenta is restricted to villous cytotrophoblastic cells. Placenta 28 185-191. (doi:10.1016/j. placenta.2006.03.001)

Malassine A, Frendo JL, Blaise S, Handschuh K, Gerbaud P, Tsatsaris V, Heidmann T \& Evain-Brion D 2008 Human endogenous retrovirusFRD envelope protein (syncytin 2) expression in normal and trisomy 21-affected placenta. Retrovirology 5 6. (doi:10.1186/1742-4690-5-6)

Maliniemi P, Vincendeau M, Mayer J, Frank O, Hahtola S, Karenko L, Carlsson E, Mallet F, Seifarth W, Leib-Mosch C et al. 2013 Expression of human endogenous retrovirus-w including syncytin- 1 in cutaneous T-cell lymphoma. PLOS ONE 8 e76281. (doi:10.1371/journal.pone.0076281)

Mangeney M, Renard M, Schlecht-Louf G, Bouallaga I, Heidmann O, Letzelter C, Richaud A, Ducos B \& Heidmann T 2007 Placental syncytins: genetic disjunction between the fusogenic and immunosuppressive activity of retroviral envelope proteins. PNAS 104 20534-20539. (doi:10.1073/pnas.0707873105)

Menendez L, Benigno BB \& McDonald JF 2004 L1 and HERV-W retrotransposons are hypomethylated in human ovarian carcinomas. Molecular Cancer 3 12. (doi:10.1186/1476-4598-3-12)

Mi S, Lee X, Li X, Veldman GM, Finnerty H, Racie L, LaVallie E, Tang XY, Edouard P, Howes S et al. 2000 Syncytin is a captive retroviral envelope protein involved in human placental morphogenesis. Nature $\mathbf{4 0 3}$ 785-789. (doi:10.1038/35001608)

Mo H, Ouyang D, Xu L, Gao Q \& He X 2013 Human endogenous retroviral syncytin exerts inhibitory effect on invasive phenotype of B16F10 melanoma cells. Chinese Journal of Cancer Research 25 556-564. (doi:10.3978/j.issn.1000-9604.2013.10.06)

Mondestin MA, Ananth CV, Smulian JC \& Vintzileos AM 2002 Birth weight and fetal death in the United States: the effect of maternal diabetes during pregnancy. American Journal of Obstetrics and Gynecology 187 922-926. (doi:10.1067/mob.2002.127458)

Mortensen K, Lichtenberg J, Thomsen PD \& Larsson LI 2004 Spontaneous fusion between cancer cells and endothelial cells. Cellular and Molecular Life Sciences 61 2125-2131. (doi:10.1007/s00018-004-4200-2)

Muir A, Lever AM \& Moffett A 2006 Human endogenous retrovirus-W envelope (syncytin) is expressed in both villous and extravillous trophoblast populations. Journal of General Virology 87 2067-2071. (doi:10.1099/vir.0.81412-0)

Muroi Y, Sakurai T, Hanashi A, Kubota K, Nagaoka K \& Imakawa K 2009 CD9 regulates transcription factor GCM1 and ERVWE1 expression through the CAMP/protein kinase A signaling pathway. Reproduction 138 945-951. (doi:10.1530/REP-09-0082)
Nelissen EC, van Montfoort AP, Dumoulin JC \& Evers JL 2011 Epigenetics and the placenta. Human Reproduction Update 17 397-417. (doi:10.1093/humupd/dmq052)

Nilsson BO, Jin M, Andersson AC, Sundstrom P \& Larsson E 1999 Expression of envelope proteins of endogeneous C-type retrovirus on the surface of mouse and human oocytes at fertilization. Virus Genes $\mathbf{1 8}$ 115-120. (doi:10.1023/A:1008004332513)

Nishimura H, Cho C, Branciforte DR, Myles DG \& Primakoff P 2001 Analysis of loss of adhesive function in sperm lacking cyritestin or fertilin beta. Developmental Biology 233 204-213. (doi:10.1006/ dbio.2001.0166)

Nixon B, Aitken RJ \& McLaughlin EA 2007 New insights into the molecular mechanisms of sperm-egg interaction. Cellular and Molecular Life Sciences 64 1805-1823. (doi:10.1007/s00018-007-6552-x)

O'Sullivan JB, Harris MI \& Mills JL 1985 Maternal diabetes in pregnancy. In Diabetes in America, pp 1-17. Bethesda, MD, USA: National Institute of Diabetes and Digestive and Kidney Diseases.

Prudhomme S, Bonnaud B \& Mallet F 2005 Endogenous retroviruses and animal reproduction. Cytogenetic and Genome Research 110 353-364. (doi:10.1159/000084967)

Raghupathy R 1997 Th1-type immunity is incompatible with successful pregnancy. Immunology Today 18 478-482. (doi:10.1016/S01675699(97)01127-4)

Rawn SM \& Cross JC 2008 The evolution, regulation, and function of placenta-specific genes. Annual Review of Cell and Developmental Biology 24 159-181. (doi:10.1146/annurev.cellbio.24.110707.175418)

Rote NS, Chakrabarti S \& Stetzer BP 2004 The role of human endogenous retroviruses in trophoblast differentiation and placental development. Placenta 25 673-683. (doi:10.1016/j.placenta.2004.02.008)

Ruchat SM, Houde AA, Voisin G, St-Pierre J, Perron P, Baillargeon JP, Gaudet D, Hivert MF, Brisson D \& Bouchard L 2013 Gestational diabetes mellitus epigenetically affects genes predominantly involved in metabolic diseases. Epigenetics 8 935-943. (doi:10.4161/epi.25578)

Ruebner M, Strissel PL, Langbein M, Fahlbusch F, Wachter DL, Faschingbauer F, Beckmann MW \& Strick R 2010 Impaired cell fusion and differentiation in placentae from patients with intrauterine growth restriction correlate with reduced levels of HERV envelope genes. Journal of Molecular Medicine 88 1143-1156. (doi:10.1007/s00109010-0656-8)

Smallwood A, Papageorghiou A, Nicolaides K, Alley MK, Jim A, Nargund G, Ojha K, Campbell S \& Banerjee S 2003 Temporal regulation of the expression of syncytin (HERV-W), maternally imprinted PEG10, and SGCE in human placenta. Biology of Reproduction 69 286-293. (doi:10.1095/biolreprod.102.013078)

Soygur B, Sati L \& Demir R 2016 Altered expression of human endogenous retroviruses syncytin-1, syncytin-2 and their receptors in human normal and gestational diabetic placenta. Histol Histopathol 31 1037-1047. (doi:10.14670/HH-11-735)

Stoye JP 2012 Studies of endogenous retroviruses reveal a continuing evolutionary saga. Nature Reviews Microbiology 10 395-406. (doi:10.1038/nrmicro2783)

Strick R, Ackermann S, Langbein M, Swiatek J, Schubert SW, Hashemolhosseini S, Koscheck T, Fasching PA, Schild RL, Beckmann MW \& Strissel PL 2007 Proliferation and cell-cell fusion of endometrial carcinoma are induced by the human endogenous retroviral Syncytin-1 and regulated by TGF-beta. Journal of Molecular Medicine 85 23-38. (doi:10.1007/s00109-006-0104-y)

Strissel PL, Ruebner M, Thiel F, Wachter D, Ekici AB, Wolf F, Thieme F, Ruprecht K, Beckmann MW \& Strick R 2012 Reactivation of codogenic endogenous retroviral (ERV) envelope genes in human endometrial carcinoma and prestages: emergence of new molecular targets. Oncotarget 3 1204-1219. (doi:10.18632/oncotarget)

Sugimoto J, Sugimoto M, Bernstein H, Jinno Y \& Schust D 2013 A novel human endogenous retroviral protein inhibits cell-cell fusion. Scientific Reports 3 1462. (doi:10.1038/srep01462)

Tolosa JM, Schjenken JE, Clifton VL, Vargas A, Barbeau B, Lowry P, Maiti K \& Smith R 2012 The endogenous retroviral envelope protein syncytin-1 inhibits LPS/PHA-stimulated cytokine responses in human blood and is sorted into placental exosomes. Placenta 33 933-941. (doi:10.1016/j. placenta.2012.08.004)

Toufaily C, Lokossou AG, Vargas A, Rassart E \& Barbeau B 2015 A CRE/AP1 -like motif is essential for induced syncytin-2 expression and fusion in 
human trophoblast-like model. PLOS ONE 10 e0121468. (doi:10.1371/ journal.pone.0121468)

Trejbalova K, Blazkova J, Matouskova M, Kucerova D, Pecnova L, Vernerova Z, Heracek J, Hirsch I \& Hejnar J 2011 Epigenetic regulation of transcription and splicing of syncytins, fusogenic glycoproteins of retroviral origin. Nucleic Acids Research 39 8728-8739. (doi:10.1093/ nar/gkr562)

Valadi H, Ekstrom K, Bossios A, Sjostrand M, Lee JJ \& Lotvall JO 2007 Exosome-mediated transfer of mRNAs and microRNAs is a novel mechanism of genetic exchange between cells. Nature Cell Biology 9 654-659. (doi:10.1038/ncb1596)

Vargas A, Moreau J, Landry S, LeBellego F, Toufaily C, Rassart E, Lafond J \& Barbeau B 2009 Syncytin-2 plays an important role in the fusion of human trophoblast cells. Journal of Molecular Biology 392 301-318. (doi:10.1016/j.jmb.2009.07.025)

Vargas A, Toufaily C, LeBellego F, Rassart E, Lafond J \& Barbeau B 2011 Reduced expression of both syncytin 1 and syncytin 2 correlates with severity of preeclampsia. Reproductive Sciences 18 1085-1091. (doi:10.1177/1933719111404608)

Vargas A, Zhou S, Ethier-Chiasson M, Flipo D, Lafond J, Gilbert C \& Barbeau B 2014 Syncytin proteins incorporated in placenta exosomes are important for cell uptake and show variation in abundance in serum exosomes from patients with preeclampsia. FASEB Journal $\mathbf{2 8}$ 3703-3719. (doi:10.1096/fj.13-239053)

Vassilopoulos G, Wang PR \& Russell DW 2003 Transplanted bone marrow regenerates liver by cell fusion. Nature 422 901-904. (doi:10.1038/ nature01539)

Villesen P, Aagaard L, Wiuf C \& Pedersen FS 2004 Identification of endogenous retroviral reading frames in the human genome. Retrovirology 1 32. (doi:10.1186/1742-4690-1-32)

Vinogradova T, Volik S, Lebedev Y, Shevchenko Y, Lavrentyeva I, Khil P, Grzeschik KH, Ashworth LK \& Sverdlov E 1997 Positioning of 72 potentially full size LTRs of human endogenous retroviruses HERV-K on the human chromosome 19 map. Occurrences of the LTRs in human gene sites. Gene 199 255-264. (doi:10.1016/S0378-1119(97)00376-4)

Voisset C, Blancher A, Perron H, Mandrand B, Mallet F \& Paranhos-Baccala G 1999 Phylogeny of a novel family of human endogenous retrovirus sequences, HERV-W, in humans and other primates. AIDS Research and Human Retroviruses 15 1529-1533. (doi:10.1089/088922299309810)

Wang LJ, Cheong ML, Lee YS, Lee MT \& Chen H 2012 High-temperature requirement protein A4 (HtrA4) suppresses the fusogenic activity of syncytin-1 and promotes trophoblast invasion. Molecular and Cellular Biology 32 3707-3717. (doi:10.1128/MCB.00223-12)

West NA, Kechris K \& Dabelea D 2013 Exposure to maternal diabetes in utero and DNA methylation patterns in the offspring. Immunometabolism 1 1-9. (doi:10.2478/immun-2013-0001)

Wiener F, Klein G \& Harris H 1974 The analysis of malignancy by cell fusion. V. Further evidence of the ability of normal diploid cells to suppress malignancy. Journal of Cell Science 15 177-183.

Wilson ML, Goodwin TM, Pan VL \& Ingles SA 2003 Molecular epidemiology of preeclampsia. Obstetrical and Gynecological Survey 58 39-66. (doi:10.1097/00006254-200301000-00022)

Yu C, Shen K, Lin M, Chen P, Lin C, Chang GD \& Chen H 2002 GCMa regulates the syncytin-mediated trophoblastic fusion. Journal of Biological Chemistry 277 50062-50068. (doi:10.1074/jbc.M209316200)

Zhang XY, Loflin PT, Gehrke CW, Andrews PA \& Ehrlich M 1987 Hypermethylation of human DNA sequences in embryonal carcinoma cells and somatic tissues but not in sperm. Nucleic Acids Research 15 9429-9449. (doi:10.1093/nar/15.22.9429)

Zhou H, Li J, Podratz KC, Tipton T, Marzolf S, Chen HB \& Jiang SW 2014 Hypomethylation and activation of syncytin-1 gene in endometriotic tissue. Current Pharmaceutical Design 20 1786-1795. (doi:10.2174/13 816128113199990540)

Zhuang XW, Li J, Brost BC, Xia XY, Chen HB, Wang CX \& Jiang SW 2014 Decreased expression and altered methylation of syncytin-1 gene in human placentas associated with preeclampsia. Current Pharmaceutical Design 20 1796-1802. (doi:10.2174/13816128113199990541)

Received 19 January 2016

First decision 11 March 2016

Revised manuscript received 15 July 2016

Accepted 1 August 2016 